\title{
A Survey on Electric and Hybrid Electric Vehicle Technology
}

\author{
Samuel E. de Lucena \\ Unesp - São Paulo State University \\ Brazil
}

\section{Introduction}

Internal combustion engine vehicles (ICEVs) have experienced continuous development in manufacturing technology, materials science, motor performance, vehicle control, driver comfort and security for more than a century. Such ICEV evolution was accompanied by the creation of a huge network of roads, refuelling stations, service shops and replacement part manufacturers, dealers and vendors. No doubt, these fantastic industrial activities and business have had a central role in shaping the world and, in many aspects, the society as well. Today, the number of ICEV models and applications is astonishing, ranging from small personal transport cars to a hundred passenger buses, to heavy load and goods transportation trucks and heavy work caterpillars. Modern ICE vehicles encompass top comfort, excellent performance and advanced security, for relatively low prices and, needless to say, have become since the beginning the most attractive consumer products. However, despite approximately a century-long industry and academia struggle to improve ICE efficiency, this is, and will continue to be, incredibly low. As illustrated in Fig. 1, solely circa $30 \%$ of the energy produced in the ICE combustion reaction is converted into mechanical power. In other words, approximately $70 \%$ of the energy liberated by combustion is lost. In fact and worse than that, the wasted energy of thermal motors, as ICEs may be called, is transformed into motor and exhaust gases heat. The exhaust gases are a blend formed mostly of carbon dioxide $\left(\mathrm{CO}_{2}\right)$ and, to a lower extent, nitrogen oxides $\left(\mathrm{NO}_{\mathrm{x}}\right)$, hydrocarbons $\left(\mathrm{C}_{\mathrm{x}} \mathrm{H}_{\mathrm{y}}\right)$, carbon monoxide $(\mathrm{CO})$ and soot. Carbon dioxide is known to block the earth's radiation emissions back into the outer space thus promoting global temperature rise - the so-called greenhouse effect. This, climate researchers say, is silently creating other global catastrophic changes, as for example, sea level rise. Air pollution in big cities is another serious problem caused by exhaust gases, which leads to respiratory system diseases, including lung cancer. Disturbing noise level is another issue related to big fleet of ICEVs in big cities. Yet, this brings about another headache for city administrators and authorities: the daily jamming, though this last nuisance might be alleviated only by mass transport systems (i.e., subways and trains).

Whether none of the above listed problems ever existed, yet a challenging situation had to be dealt with urgently: the finite amount of fossil fuel available for an ever-increasing world fleet. As petrol wells vanish, this commodity price skyrockets, also motivated by political tension around production areas in Middle East. On the other hand, renewable energy 
sources, like ethanol produced from sugarcane or maize crops, are an alternative solution being tried in some countries. In Brazil, for instance, sugarcane bio-fuel is an established option, with more than two decades on the road, with ICE automobiles prepared to run interchangeably on gasoline or ethanol automatically. Any driver could choose which fuel type to use at the refuelling station, much based on their prices. There is a criticism over this solution as regards to the demands on food availability and prices, once crop fields are used to produce bio-fuels instead of food. Greenhouse effect gas generation and air pollution problems are still present though to a somewhat lower extent.

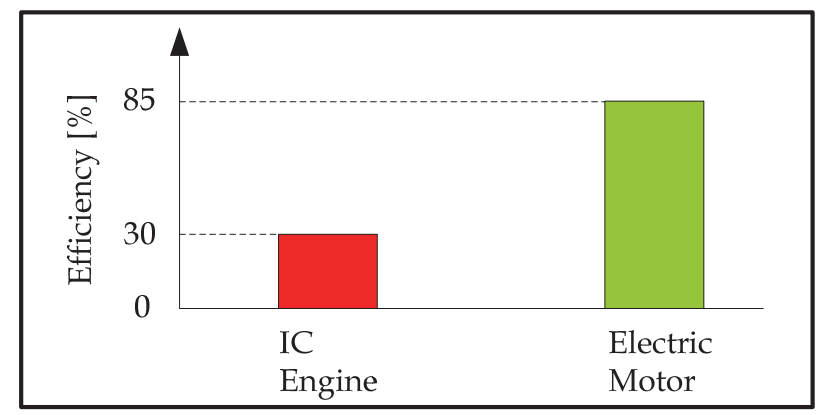

Fig. 1. ICEs are very inefficient energy converters as compared to electric motors

An accurate look at Fig. 1 reveals that electric motors are far superior to ICE and could do an excellent job in propulsion of vehicles, helping to solve the serious climate, air pollution and noise problems created by ICEVs. As a matter of fact, electric vehicles (EVs) were invented in 1834, before ICE vehicles, being manufactured by several companies of the U.S.A, England, and France (Chan, 2007). Fig. 2(a) shows a picture of commercial EV in 1920. Poor performance of their batteries contrasting to fast development of ICE technology, extremely high energy density and power density of gasoline and petrol, and the abundance and low price offer of fossil fuel, all conspired against those days' EVs that rapidly became defunct. Interestingly, more than 150 years later, triggered by the world energy crisis in the 1970s, EVs entered the agendas of world's greatest carmakers, governments' energy and climate policy, and of worldwide non-governmental organizations worried about environmental pollution and greenhouse effect.

Today, although their sales are negligible in relation to that of ICEVs, pure EVs and hybrid EVs (HEVs), i.e., those that combine ICE with electrical machines fed by batteries or fuel cells (hydrogen derived electricity), are offered by world's greatest carmakers. The performance of HEVs, from the driver's standpoint, rivals or outdoes that of modern ICEVs. Their energy consumption ranges from circa $10 \%$ to $70 \%$ lower than that of an equivalent ICE car, depending on their power, battery size, control strategy, etc. For the sake of illustration, until 2008, Toyota Prius, the world's first commercially mass-produced and marketed HEV, sold over 500,000 units on the world's market (Xiang et al., 2008). Fig. 2(b) shows a photograph of a modern 2010 Toyota Prius HEV whose selling price begins at 23,000 USD.

The dramatic gain in energy efficiency, besides much lower or zero gas emission and noisefree operation, is due to the much higher efficiency of electric motors and control strategies such as regenerative braking and storage of excess energy from the ICE during coasting. 


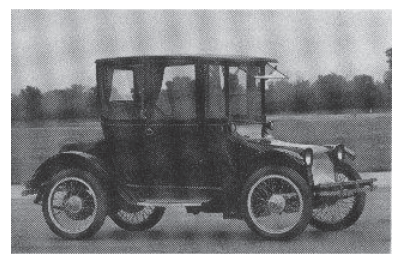

(a)

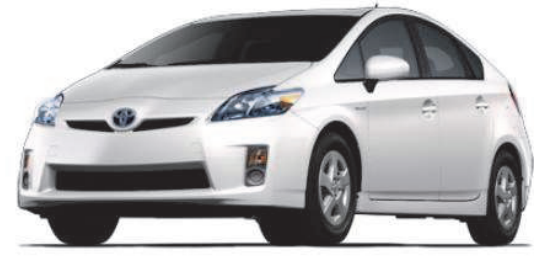

(b)

Fig. 2. a) 1920 Detroit Electric b) 2010 Toyota Prius (HEV) [Toyota Motor Co., 2011]

There are many reasons for EVs and HEVs to represent so low a share of today's car market. For EVs, the most important are their shorter range, the lack of recharging infrastructure, and higher initial cost. Though HEVs feature range, performance and comfort equivalent or better than ICEVs, their initial cost is higher and the lack of recharging infrastructure is a great barrier for their diffusion. Nevertheless, the energy efficiency of the latter, though far higher than that of ICEVs', seems not capable of solving the greenhouse gas emissions by world vehicle fleet. And this situation is expected to become worse and worse, given that world fleet is expected to triple by 2050, in relation to 2000, due to massive car use in countries such as China, India and Brazil. To limit the planet's average temperature to 2-2.4 ${ }^{\circ} \mathrm{C}$ above the pre-industrial era level, scientists calculate a needed reduction of $50-85 \%$ in $\mathrm{CO}_{2}$ emissions in all sectors by 2050. EVs may play a fundamental role in this struggle, given that the transportation sector is one of the largest emitters of $\mathrm{CO}_{2}$ (Bento, 2010). To that end, industry, government, and academia must strive to overcome the huge barriers that block EVs widespread use: battery energy and power density, battery weight and price, and battery recharging infrastructure.

This chapter presents a synthetic review on the technology of modern EVs. This includes the types and classification of EVs, electric motor kinds employed by EV manufacturers, power electronics driver topologies, control strategies, battery types and performance, and infrastructure demands.

\section{General classification of electric vehicles}

A more universal classification of the many different types of electric vehicles will certainly appear, perhaps in a near future, as a result of their mass production, originating from carmaker associations and research teams efforts worldwide. As a matter of fact, a literature review makes it clear that a nomenclature convergence is already easily perceived. This nomenclature is stronger and more definitive when EVs classification is carried out based on either the energy converter type(s) used to propel the vehicles or the vehicles' power and function (Chan, 2007; Maggetto \& van Mierlo, 2000). When referring to the energy converter types, by far the most used EV classification, two big classes are distinguished, as depicted in Fig. 3, namely: battery electric vehicles (BEVs), also named pure electric vehicle, and hybrid electric vehicles (HEVs). BEVs use batteries to store the energy that will be transformed into mechanical power by electric motor(s) only, i. e., ICE is not present. In hybrid electric vehicles(HEVs), propulsion is the result of the combined actions of electric motor and ICE. The different manners in which the hybridization can occur give rise to different architectures: series hybrid, parallel hybrid, series-parallel hybrid, and complex hybrid, 
which are here detailed in separate sections. As the reader may expect, there is no universal architecture that can be considered superior in all practical aspects: energy efficiency, vehicle performance and range, driver comfort, manufacturing complexity, and production cost. Therefore, in practice, carmakers may choose different architectures to achieve different goals and meet distinct transport segment requirements.

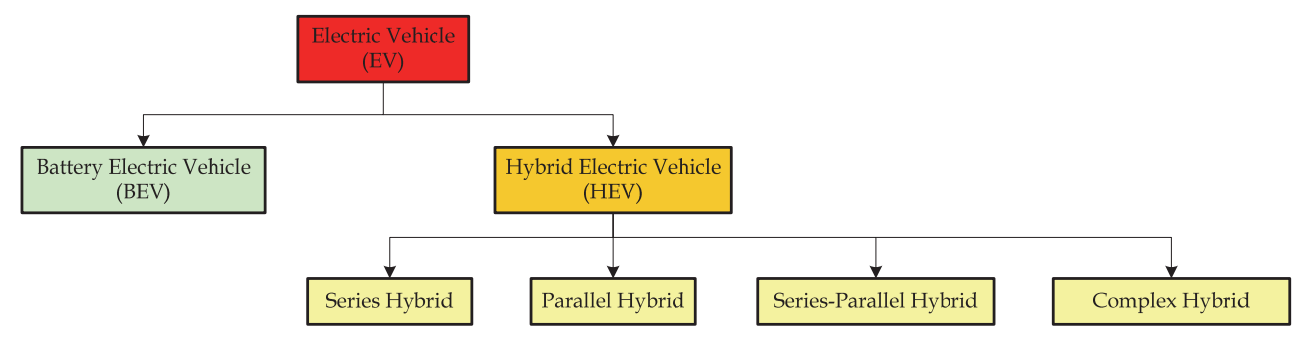

Fig. 3. Classification of EVs according to the type(s) and combination (if any) of energy converters used (electric motor \& ICE)

Under the large umbrella of HEVs, there is another category (not shown in Fig. 3) that utilizes a fuel cell instead of an ICE together with the electric motor, always in the serieshybrid architecture. This is the fuel cell vehicle (FCV). The following rationale is to justify FCVs absence in Fig. 3 and in the rest of this chapter. The hydrogen-based chemical reaction of FCVs generates the electricity either to be used by the EM or stored in battery or supercapacitor. The by-product of hydrogen and oxygen reaction is simply pure water, which renders FCVs emission-free and consequently an environmentally friendly technology (Gulhane et al., 2006). A recent research about the dynamic competition for market between plug-in HEVs (PHEVs) and FCVs showed that the early deployment PHEVs is almost certain to close the market for FCV in the future (Bento, 2010). Another study shows that from 2006 onwards auto makers decreased sharply the prototyping activities with FCVs and much of the public funding in the U.S.A. and other industrial countries shifted from FCVs to BEVs and PHEVs. Despite some controversy over the reasons, which range from the lack of a hydrogen infrastructure, absence of a technological breakthrough in hydrogen technology, to very high cost production of FCVs (Honda FCX Clarity, an FCV most close to market, costs circa 1 million USD, clearly not an attractive pricing), as a matter of fact these vehicles do not seem an option anymore (Bakker, 2010). Nevertheless, hopefully fuel cells may play a very important role in replacing ICE of stationary machines.

A second useful classification for HEVs (Fig. 4) places them into the following three categories, according to the electric motor power under the hood: micro hybrid, mild hybrid, and full hybrid (Chan, 2007). In effect, this classification is a measure of the hybridization degree of the HEV (Maggetto, 2000). In other words, it indicates how much important is the role played by the electric motor in the car propulsion. Micro hybrids use electric motor of about $2.5 \mathrm{~kW}$ at $12 \mathrm{~V}$. The EM is only a helping hand to the ICE, in the start and stop operations, which dominate in city driving. Even in this driving mode, energy savings is of only about $5 \%$ to $10 \%$. This is a very poor economy, obviously with a negligible impact on fossil fuel dependence, metropolitan area air pollution and greenhouse gas emissions, the challenging triad. C3 Citroen is a commercial example. EM in mild hybrids is of $10-20 \mathrm{~kW}$ at 
$100-200 \mathrm{~V}$. As expected, energy savings is greater and reaches about $20 \%-30 \%$. Commercial models are Honda Civic and Honda Insight. Though fuel (and thus operational) economy may compensate for their greater initial cost as compared to ICE equivalents, turning mild HEVs attractive for consumers, from the aforementioned triad's viewpoint, even if massively adopted, they could not be a remedy, given the targeted global $\mathrm{CO}_{2}$ reduction and, even worse, if one takes into account that world fleet (vastly of ICE vehicles) is increasing more and more, as new consumers come into life in emerging countries. For the sake of illustration, only in Brazil, passenger car fleet doubled in the last decade. The last member of this category is the full hybrid, which embeds an EM of circa $50 \mathrm{~kW}$ at 200-300 V and, in city driving, yields energy saving of 30\%-50\%, thanks to complex control algorithms that manage to operate the ICE, when needed, always at maximum efficient region, directing the excess energy to batteries. Energy is also recovered and saved into the battery and/or supercapacitor, during coasting and regenerative breaking. Toyota Prius is a genuine member of this family. Though full hybrids can be an auxiliary player to combat the triad, their efficiency figures are much less than needed to curb the triad by themselves, for the same reasons discussed above. At best, in this author's opinion, they serve to delay the climate tragedy and to give some psychological relief to their owners.

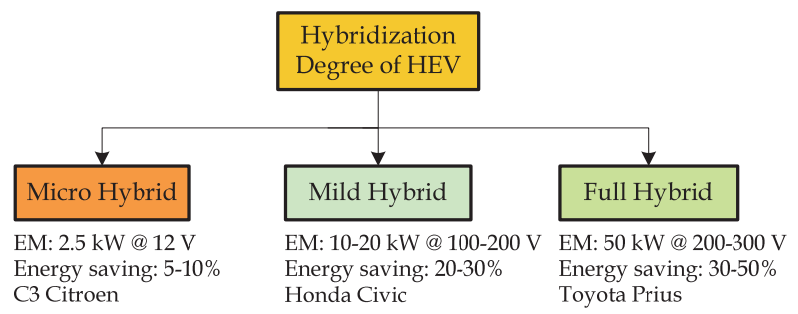

Fig. 4. Classification of EVs according to the hybridization degree (EM: electric motor) (Chan, 2007)

A last classification for HEVs divides the automobile market into a number of categories (or segments) mostly based on their prices (Maggetto, 2000). Five segments are identified, as depicted in Fig. 5. HEVs of the second family-car segment are for frequent use in town and move a relatively low daily distance. If propelled mainly by ICE, in urban areas, the overall efficiency is very low. Conversely, if propulsion relies only on electric motor, high efficiency can be reached, and an effective combat to the triad (greenhouse gas emission, air pollution, and fossil fuel dependence) might be given. The ICE (with its fuel tank) might serve as a range extender, in practice, an efficient manner to null drivers' anxiety of being run out of charge. Even though this classification has been used for HEVs, it is interesting to extend it to BEVs since, as discussed just above, the latter can play a very important role in alleviating problems in metropolitan areas and world climate changes. The intermediate car segment is planned to be frequently the family's unique car. Therefore, it must be appropriate for use in town and present also a good road performance. Toyota Prius can be allocated in this segment. HEVs of the high class car segment are not convenient for city use. They feature extraordinary road performance, excellent technical performance and perfect comfort. Of course, the excellent technical performance does not take into account the environmental viewpoint. The small delivery vehicle segment is intended mainly for city use. However, 
unlike the second family car segment, vehicles of the former segment must be capable of moving a great number of relatively short-distance trips everyday. Therefore, high efficiency would be welcome, from the environmental, climate and fuel economy viewpoints. The city bus segment is dedicated to urban public transport, including tourist transport in urban areas. Vehicles of this segment feature low speed and circa $250-\mathrm{km}$ driving range. Once more, the higher the hybridization degree the better for the environment and climate. Chinese manufacturer Dongfeng argues that its EQ6121HEV hybrid bus achieves $80 \mathrm{~km} / \mathrm{h}$ and reduces in 30\% greenhouse gas emission and in $20-30 \%$, fuel consumption (Xiang et al., 2008).

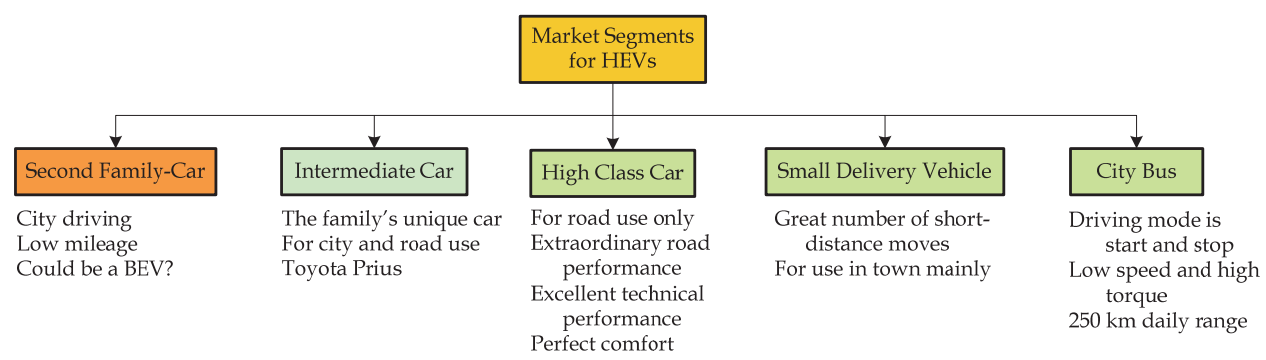

Fig. 5. Classification of EVs according to the market segment

\section{Architecture of BEVs and HEVs}

As cars go electric, new design methodologies and power train topologies come to life to optimize them according to criteria such as energy efficiency, types of energy sources, types of energy storage devices, hybridization rate, driving range, power performance, driver's comfort, production cost, ownership cost, and so on (Chen et al., 2009). As market has different demands in distinct regions of the world, and in every region there are different market segments as already discussed, it is normal that a great number of BEVs and HEVs models exist and will continue to increase (Xiang et al., 2008; Gulhane et al., 2006). Automakers strive to create car models that better fulfil the market needs, while maximize their income.

\subsection{BEVs architectures}

Fig. 6 illustrates one of the simplest topology for battery-electric vehicles. The energy stored in the battery (or in a battery pack) is used by the power converter to drive the electric motor. This, in turn, drives the two wheels by means of a fixed or changeable gear and a power splitting differential gear. The power converter unit may include a dc-dc converter and a motor driver. It all depends on the motor type and ratings and on the battery voltage, energy and power density. For maximum efficiency, the vehicle's kinetic energy must be converted to electrical energy by the motor/generator and stored in the battery pack via the power converter, whenever the break pedal is pressed and during coasting. Of course, the electronic detail of the power converter (e.g., topology, control strategy) is a function of the employed motor type, battery technology and ratings, etc. Anyway, in order to regenerate energy, the power converter must be able to control the power flow in both directions: from the battery to the motor as well as from the motor to the battery. If the battery type cannot 
be fast charged with the recovered kinetic energy, either a supercapacitor or a flywheel may be used for temporary energy storage. If possible, the changeable (or fixed) gear may be cut out, to diminish the mechanical parts counting. In this case, it is replaced by more complex variable speed controller for the motor.

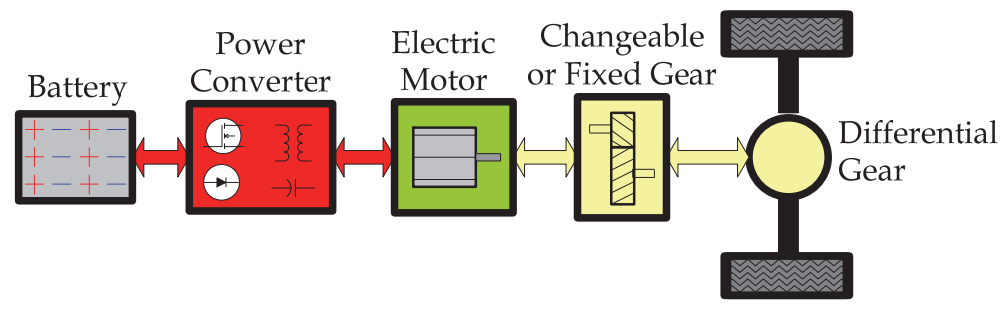

Fig. 6. One-motor BEV

Pure electric vehicles may adopt two (or four) in-wheel motors in their powertrains, as sketched in Fig. 7. In this case, every motor is driven by a dedicated power converter that must control wheel's speed and torque. Moreover, a central electronic controller must coordinate speed differences (in steering wheels), whenever needed or as a result of wheel slippage, as long as a differential power splitting device is no more present. As expected, the simplification of the mechanical design is attained at the expense of increased complexity of the power electronics and controllers. On the other hand, augmenting the motor number, for a desired vehicle power and performance, leads to significantly smaller motors and, what is less obvious, to lower rated power switches and passive electronic parts, which influence on drive cost and reliability. One interesting operating mode for multiple-motor BEVs is that the vehicle can continue to operate, though at a somewhat reduced power, if one of the motors (in case of two-motor BEVs) gets out of service. Comparing Figs. 7 and 6, one notices that in-wheel motor propulsion topology reduces radically EV's number of mechanical links.

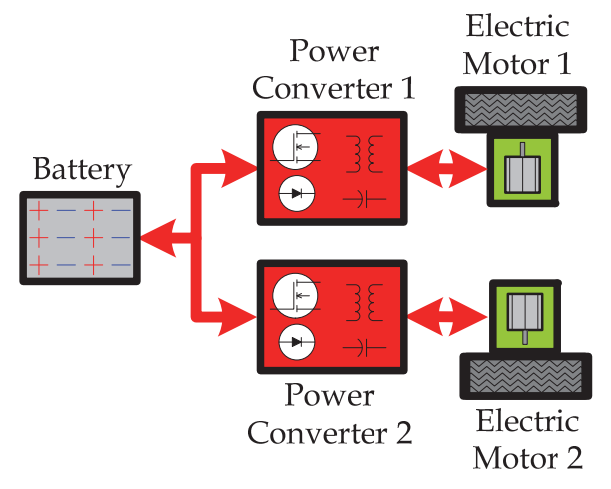

Fig. 7. Two-motor BEV

To this date, owing to battery limitations such as high initial cost, relatively low energy and power density, and excessive weight, BEVs are not as attractive as HEVs, because of limited 
driving range, performance and comfort. Nevertheless, as BEVs are the only zero-emission cars, they must be viewed as an effective tool to combat greenhouse gas emissions, air pollution and petrol dependency. There are arguments to reinforce the idea that strong governmental incentive policies should be adopted in as many countries as possible to benefit owners of BEVs. Examples of such incentives are: government rebate to each BEV owner (say 10\% of vehicle price), exemption of purchase tax, exemption of road maintenance fee, road passing fee and parking fee. In some countries some of these actions are under way (Xiang et al., 2008). Data of the U. S. Department of Transportation reveal that $50 \%$ of daily vehicle travel is less than $48 \mathrm{~km}$ and average daily vehicle trip is about 16 $\mathrm{km}$ (Kruger \& Leaver, 2010). Today's batteries feature enough energy to easily enable secondcar family BEVs (though this class was originally proposed to HEVs) to travel these distances without recharge. Therefore, there is room for a massive production (and adoption) of pure electric vehicles. However, the massive use of BEVs will be no good from the carbon emission viewpoint, if fossil fuel (coal or petrol) is used to generate the electricity that is ultimately put into the car batteries. To be effective, car batteries must be recharged with energy coming from carbon-free resources (such as solar, wind, hydro, and nuclear). On the other hand, every country must study its grid capacity to deal with a big number of new (and of special profile) consumers. The impact of massive use of BEVs on the power grid might be considerable. Yet, in the future, BEVs can serve as distributed energy storage devices that may play an important role in regulating energy demand.

\subsection{HEVs architectures}

While BEVs are propelled by electric motors only, HEVs employ both ICE and electric motor in their powertrains. The way these two energy converters are combined to propel the vehicle determines to the three basic powertrain architectures: series hybrid, parallel hybrid, and series-parallel hybrid. Complex hybrid refers to architectures that cannot be classified as one of these three basic types.

\subsubsection{Series HEV}

As depicted in Fig. 8, in series HEVs the wheels are only driven by the electric motor that also operates as generator during break and coasting, augmenting thus the overall energy efficiency. This topology simplifies the powertrain design, since clutch and reduction gear are not necessary. Speed and torque control is carried out by controlling the electric motor only, which is a very efficient power converter. The ICE's role is charging (or recharging) the battery and supplying energy to the electric motor, always being operated at maximum efficiency. This is another strategy that helps increasing the overall energy efficiency. Series HEVs are said to be ICE-assisted electric vehicles, for obvious reasons. An ICE, one generator and one motor are one of the main disadvantages of series HEV. Moreover, as the vehicles must be capable of cruising with maximum load against a graded road, all the machines, i.e., the ICE, the generator and, of course, the electric motor, must be powerful enough, which will result in relatively over-dimensioned machines. This leads to cost increase. As Eq. 1 indicates (Chen et al., 2009), given the constants for initial rolling force, $F_{0}$, the rolling coefficient, $r$, the drag coefficient, $d$, the total mass (vehicle's mass plus the passenger and luggage masses), $m$, and the gravity, $g$, the resistance force, $F_{\text {res }}$, the electric motor must be capable of surpassing increases with vehicle's speed, $V$, and the road's grade, $\theta$. 


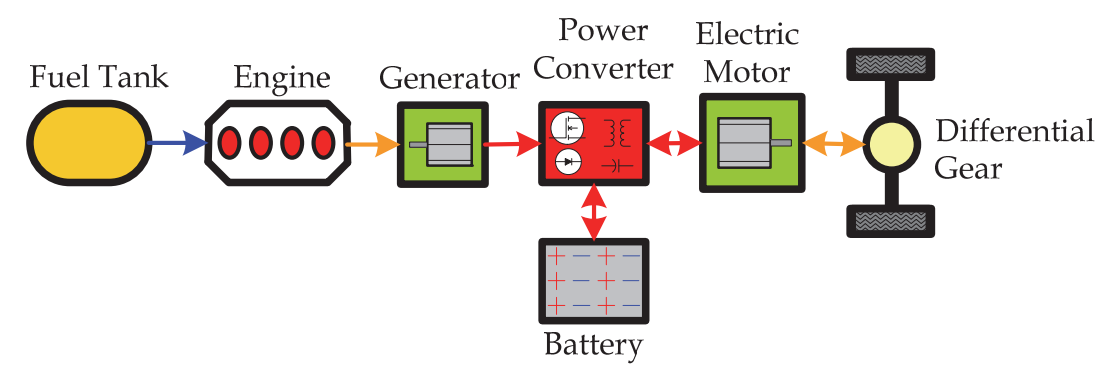

Fig. 8. Architecture of series HEV

$$
F_{r e s}=F_{0}+r V+d V^{2}+m g \sin \theta
$$

On the other hand, as indicated by Eq. 2, the motor's torque is proportional to the inertia, J, and the first derivative of angular speed, $\omega$, i.e., the angular acceleration. Eqs. 1 and 2 are interrelated to each other by the ratio of wheel to transmission radii. These two equations govern the vehicle's dynamic performance (acceleration power) and cruising speed. It is easy to note how stronger should be the powertrain if a desired series HEV had its maximum speed specification changed from, say, $80 \mathrm{~km} / \mathrm{h}$ to $120 \mathrm{~km} / \mathrm{h}$. But, is such a performance always needed? As the ICE does not add its effort to aid in propelling the vehicle, this architecture is appropriate for small HEVs, as for instance, those of the micro category or second-family car segment already mentioned, for which cruising speed can be very modest.

$$
T_{m}=J(d \omega / d t)
$$

Before proceeding to next section, it is worth making it clear that HEVs of all architectures can be recharged in two very distinct ways, as shown in Fig. 9: the so-called plug-in hybrids (PHEV) and the conventional HEVs. While PHEVs can have their batteries recharged directly from the power grid, which is an enormous advantage, the conventional HEVs have their batteries recharged by means of the ICE. In this case, the advantage is the omnipresence of gas stations. Studies indicate that conventional HEVs are potentially less eco-friendly than PHEVs. While the latter can take advantage of the ubiquitous power grid,

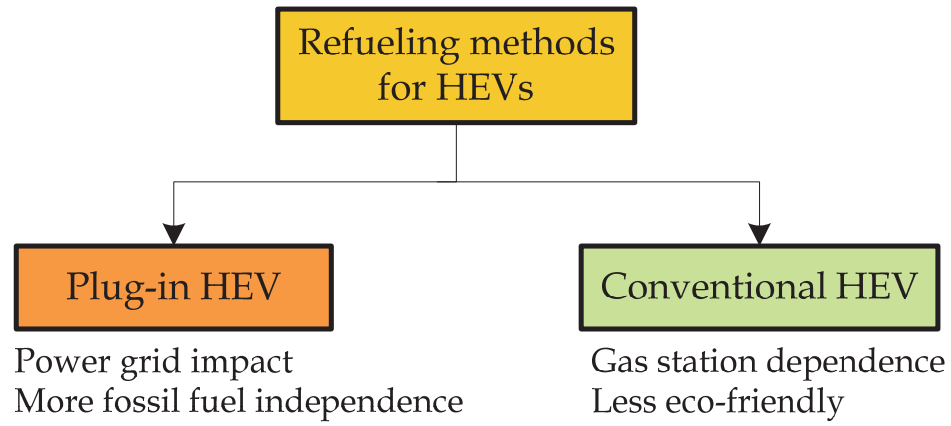

Fig. 9. Recharging methods for HEVs 
the impact they can cause to the grid is far from being negligible and depends on the way charging and discharging (as PHEVs can return stored energy to the grid) are done: controlled or not by utilities companies (Clement-Nyns et al., 2011; Sioshansi et al., 2010; Kruger \& Leaver, 2010). Moreover, if the electrical energy generated to the grid comes from fossil fuel plants, then to a great extent the environmental and climatic appeal of these vehicles is no more valid.

\subsubsection{Parallel HEV}

In parallel HEVs, propulsion can be the result of torque generated simultaneously by ICE and the electric motor. As illustrated in Fig. 10, this technology provides for independent use of the ICE and electric motor, thanks to the use of two clutches. One of the key features of parallel HEVs is that, for a given vehicle performance, the electric motor and ICE too, can be significantly smaller than that achieved with series architecture, what allows for a relatively less expensive vehicle. On the other hand, wheel propulsion by the ICE leads to superior dynamic performance of this topology. Complex powertrain controller may enable up to the following six different operation modes: electric motor on and ICE off; ICE on and electric motor off; electric motor on and ICE on, with both of them cooperating to propel the vehicle; ICE on supplying power to drive the vehicle and to drive the electric machine that, in this case, runs as generator to recharge the batteries with energy coming from the fuel tank (maximum overall energy savings can be achieved by running the ICE at maximum efficiency speed, while pumping the excess energy to the batteries); ICE on and dedicated to recharge the batteries through the electric machine (i.e., the vehicle is stopped); regenerative breaking, with energy being stored in the batteries (or in a supercapacitor), via the electric machine. This profusion of operation modes can be conveniently handled by the controller to optimize the driving performance or fuel savings, for example. Parallel HEVs are said to be electric motor-assisted ICE vehicles and their architecture are most appropriate for vehicles of the high class car segment and full hybrid. As already commented, powertrain sizing is carried out based on the desired dynamic performance for the vehicle, cruising speed, and a set of parameters such as maximum road grade, car weight, load, and so on. As expected, this activity counts heavily on computer simulation programs, before prototyping begins (Wu et al., 2011).

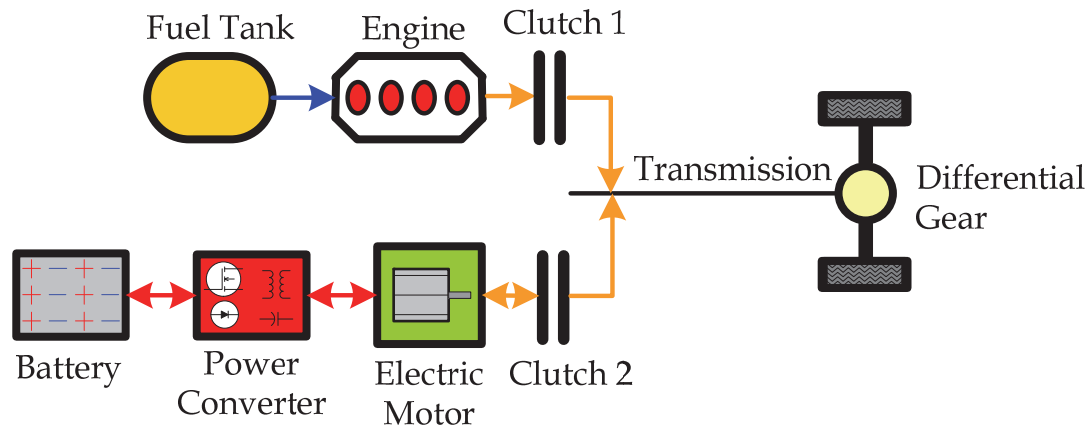

Fig. 10. Architecture of parallel HEV 


\subsubsection{Series-parallel HEV}

At the expense of one more electric generator and a planetary gear, a quite interesting architecture for the powertrain is obtained (Fig. 11), which blends features of both series and hybrid topologies, and is conveniently named series-parallel architecture. Though more expensive than any of the parent architectures, series-parallel is one of the preferred topologies for HEVs, specially when automakers target excellence in dynamic performance and high cruising speeds for their models. Like parallel HEVs, the hybridization degree is adjusted as a trade-off of performance, cruising speed, fuel economy, driveability, and comfort. As can be concluded by a rapid exam in Fig. 11, half of dozen or more operation modes are possible for series-parallel HEVs, which put pressure over the controller development and test. Needless to say, these are devised and developed with the help of computer simulators and experience.

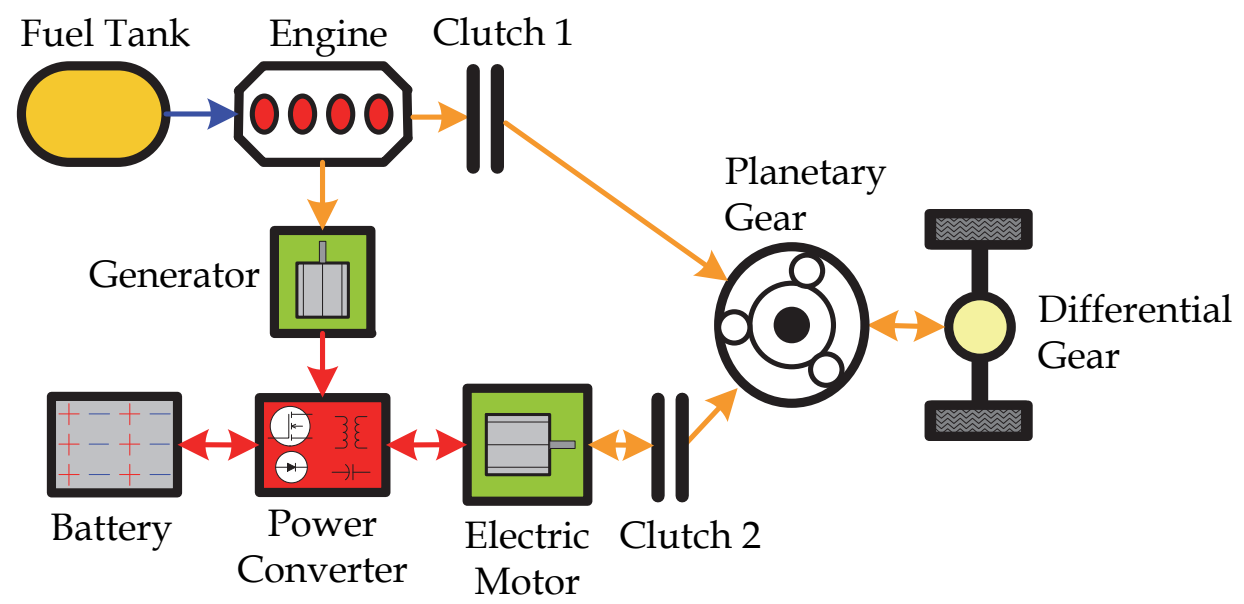

Fig. 11. Architecture of series-parallel HEV

\subsubsection{Complex HEV}

Fig. 11 sketches an architecture named complex HEV. This name is reserved to the topologies that cannot be classified as a combination (or rearrangement) of the basic architecture types analysed to this point. As can be seen in Fig. 11, two bidirectional power converters are utilized, one for the main electric motor, and another one for the auxiliary electric motor. Unlike in series-parallel HEVs, both these motors can propel the wheels concomitantly. In other words, three different torque sources add up to drive the wheels, thus leading to a better foreseeable dynamic performance vehicle and clearly higher cruising speed car. At times, the secondary electric machines operates as generator, in order to recharge the battery or to save into this the excess ICE energy, as this can run at optimal speed generating more power than needed by the vehicle. Once more, the number of possible operation modes for the complex HEVs is half a dozen or greater. Component sizing (electric motors/generators, ICE, gears, battery, power converters, etc) is a very complex task. Control program development and test are highly challenging. 


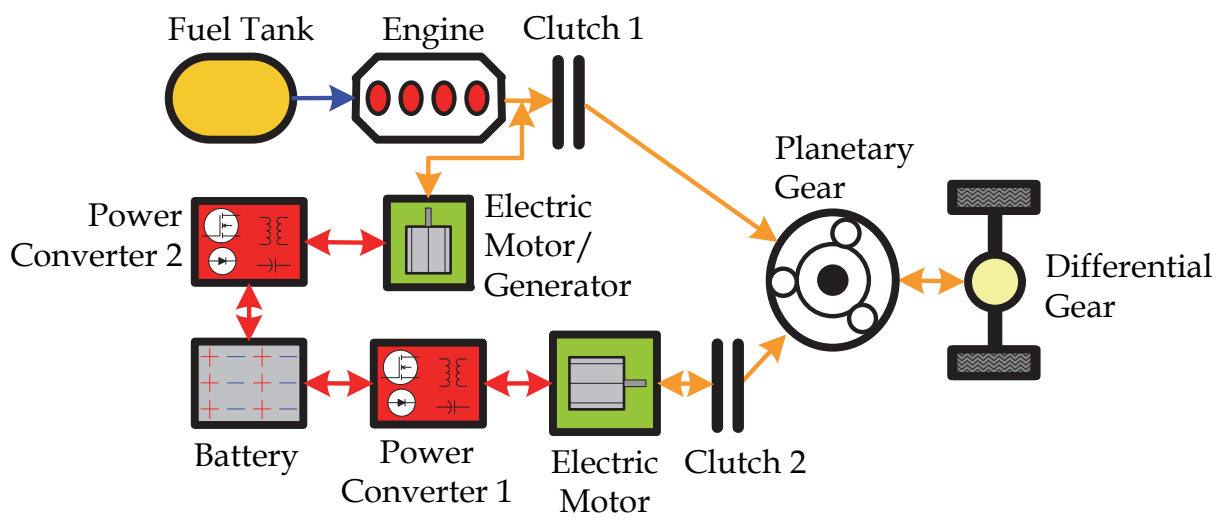

Fig. 12. Architecture of complex HEV

\section{Electric motors for EVs}

Squirrel cage rotor, three phased, asynchronous induction motors absolutely dominates the industrial applications scenario, as is largely known. Their relative low-cost, high robustness and good dynamic performance make them a good candidate for driving EVs as well. As a matter of fact, they are utilized in a number of commercial EVs. However, the dynamic performance needed by EVs is met by induction motor at a relatively high price, for the necessary vector control is a highly complex technique. Furthermore, there are drive alternatives, as illustrated in Fig. 13, that better satisfy specific EVs' demands such as high torque and power density, high efficiency over a wide torque and speed range, and wideconstant-power operating capacity (Chau et al., 2008; Gulhane et al., 2006). Permanent magnet brushless dc motor (PMBL) is a very promising technology that has been in wide

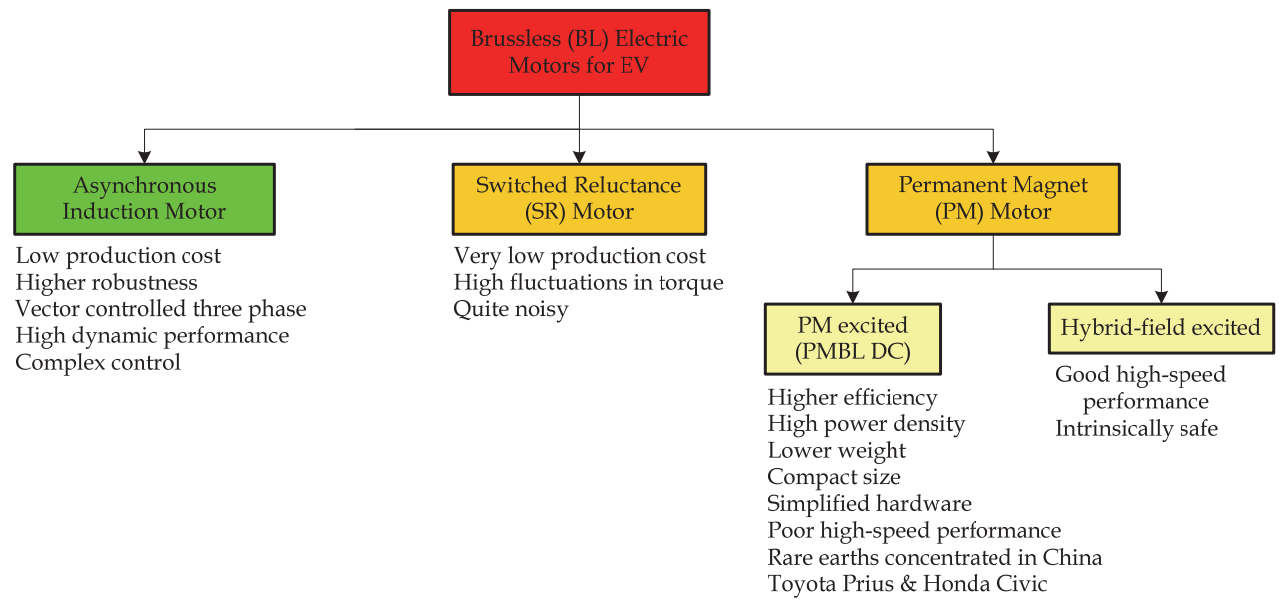

Fig. 13. Electric motor for Evs 
use with EVs. It seems this drive type will be a major market leader, though automakers outside China should be cautious and seek drive alternatives, as long as world reserves of rare earths used in the permanent magnets are practically totally situated in China, whose government could apply export restrictions. Hybrid-field excited PMBL offers superior performance, as field can be strengthened and weakened. The penalty for this choice is higher production cost and increased control complexity.

A last electromagnetic torque generator option for EVs is the brushless switched-reluctance (BLSR) motor. The very low production cost of BLSR motors (even lower than that for induction motors), together with some other important characteristics (e.g., wide speed range), make them a serious candidate for driving EVs. Nevertheless, they are plagued with (acoustic) noise and high fluctuation in torque, which might be compensated for with a more complex (and expensive) controller.

\section{Power electronics driver topologies for EVs}

Power converters are highly specialized circuits constructed with high power electronic switches and analog and digital control circuitry, to convert one unregulated dc (direct current) voltage level to either a regulated and different dc voltage level or a regulated ac (alternate current) voltage level. The former are called dc-dc converters, whereas the latter are named dc-ac converters (often called frequency inverters). In buck converters the output voltage level is lower than the input voltage level, whereas boost converters supply an elevated output voltage level relative to their inputs. Buck-boost converters may either reduce or elevate the output voltage in relation to their inputs, depending on the control signal duty cycle. Fig. 14 illustrates the application of power converters in a commercial $\mathrm{HEV}$. Converters are used to charge the battery pack from the grid voltage (in PHEV), to recharge the battery pack from the fuel tank (ICE and generator involved), to save energy into the battery pack (or ultracapacitor) during regenerative braking and coasting, as already discussed. They are used to drive the electric motor(s) and to feed the vehicle loads such as HVAC (heating, ventilation and air conditioner).

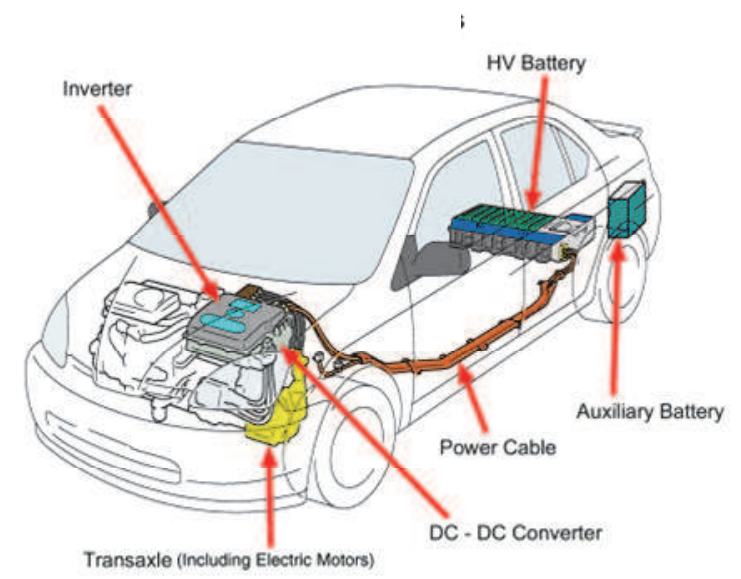

Fig. 14. Power converters in a 2001 Toyota Prius HEV [Automobile Research Bolletin, 2008] 
As illustrated in Fig. 15, classical power converter topologies, which are adequate to EVs, include the (transformer) isolated and non-isolated types and a family of bidirectional converters. Key characteristics of power converters for EVs are high efficiency (typically higher than 90\%), high reliability, electromagnetic compatibility, and miniaturization (Bellur \& Kazimierczuk, 2007). High-voltage, high-power, high temperature, fast switching and very low on-resistance semiconductor switches are of paramount importance in converters for EVs. These modern switches are metal-semiconductor oxide field-effect transistors (MOSFETs) and insulated-gate bipolar transistors (IGBT). Overall speaking, MOSFETs are faster than IGBTs, whereas these are capable of supporting high currents than MOSFETs. A number of world-class semiconductor manufacturers (such as International Rectifier, Motorola, and ST Microelectronics) develop special power switches and auxiliary circuits (as gate drivers) appropriate for EV applications. Safety is a very critical issue in EVs, for the voltages of up to $600 \mathrm{~V}$ under the hood are lethal.

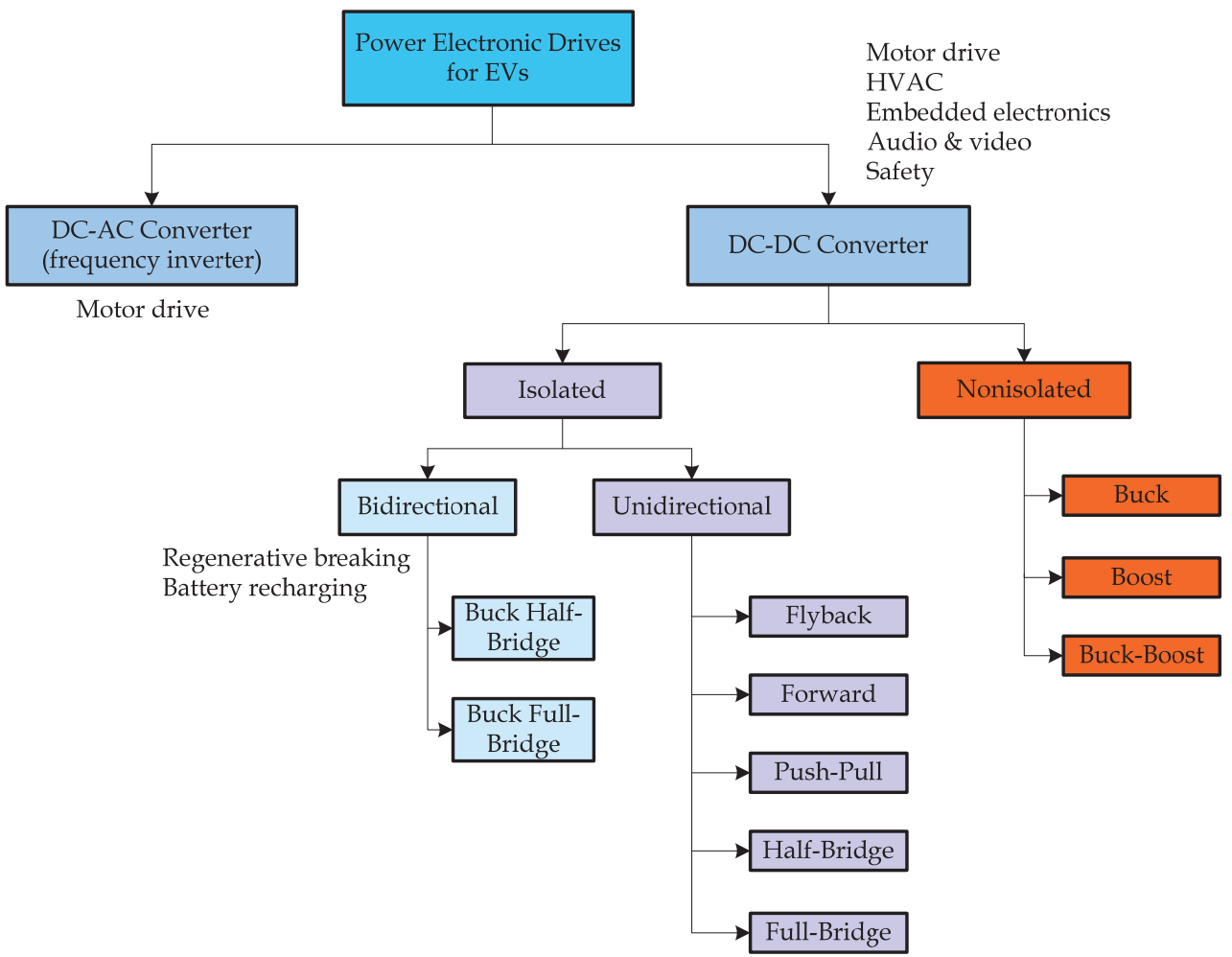

Fig. 15. Power converters for EVs

\section{Control strategies}

Control is a fundamental part of a successful EV design. Control engineering has matured for decades and nowadays counts on sophisticated microcontrollers and digital signal processors hardware and advanced integrated development environments. Despite all the 
available powerful tools and techniques, "efficient" control of EVs continues to challenge engineers and researchers, for the EVs embrace nonlinear processes (like battery behaviour), devices that are difficult to model (such as the ICE), and some conflicting goals, as for instance control for energy efficiency and control for better dynamic performance. It is not a coincidence that this area is one of the most prolific in the technical literature. Advanced digital control technique, such as optimal control and fuzzy control, are used by researchers and carmakers as they strive to improve EVs behaviour (Ambühl et al., 2010; Ohn et al., 2010).

Fig. 16 shows a power converter (frequency inverter) and a controller developed to equip a small off-road electric vehicle that is traditionally propelled by an ICE (Lucena et al., 1997). The ICE was replaced by a 3-phase induction motor and a gearbox. High voltage, high power, fast switching MOSFETs were arranged to allow for the generation of 3-phase PWM voltage to feed the induction motor. Integrated bootstrap gate drivers facilitated MOSFET control by a microcontroller. The PWM was synthesized with the aid of a look-up table containing constant voltage-to-frequency ratio sinusoidal PWM, to implement constant torque at a wide speed range (Fig. 17). The control program featured slow start function to limit current in switches and motor. The control signal comes from a potentiometer attached to the accelerator pedal.

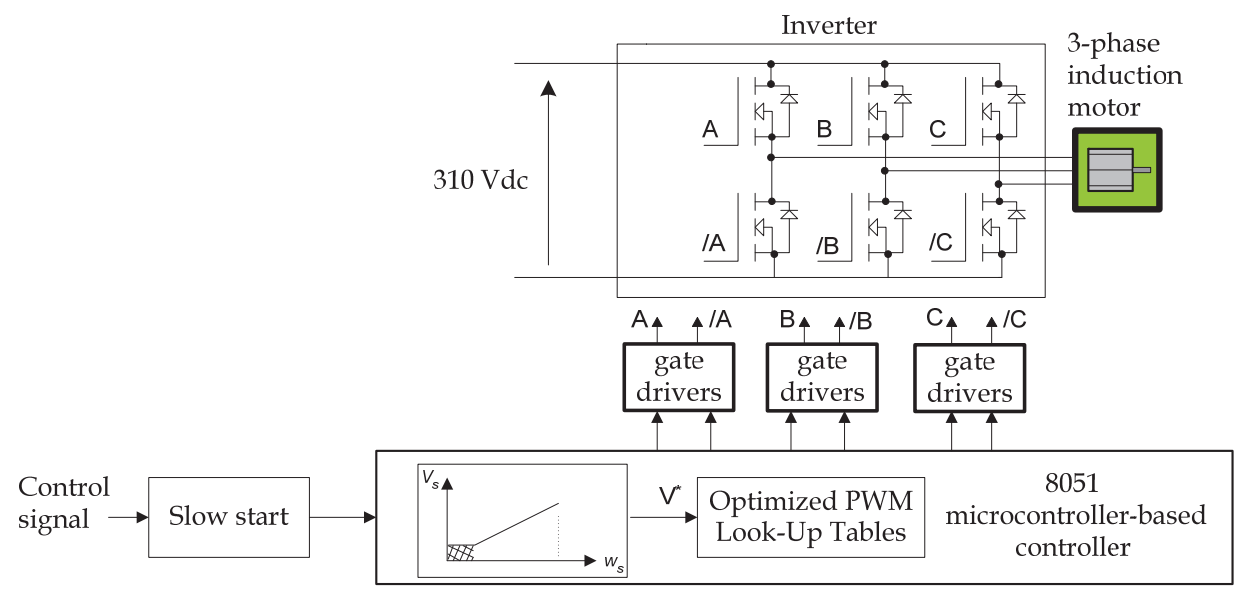

Fig. 16. Power converter and controller for 3-phase induction motor

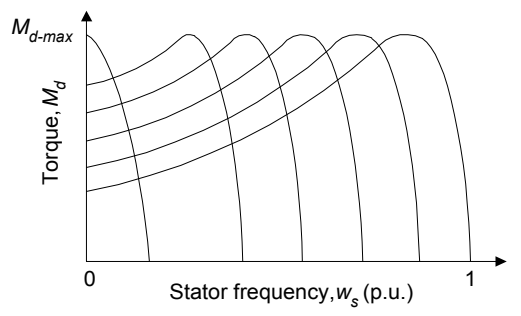

Fig. 17. Induction motor torque versus stator frequency curves at different speeds 


\section{Battery types}

Hopefully research on batteries will end up by boosting their energy and power densities as well as significantly decreasing their production cost. In a nutshell, these are the main barriers for mass diffusion of BEVs, PHEVs and conventional HEVs. Though today's technology is appropriate to EVs, from the technical viewpoint (driving range and vehicle performance), cost is still quite high for consumers.

As to the most promising technology for batteries, there seems to be no consensus among researchers. Some believe lithium-ion batteries will dominate the market for EVs (Burke, 2007), whereas others point out that nickel-metal hydride batteries are the best option (Wu et al., 2011). Meanwhile, commercial EVs are utilizing the following electrochemical technologies: Li-ion battery pack (388 V, $360 \mathrm{Ah})$, lead-acid batteries (12 V, $170 \mathrm{Ah}$ ), ironlithium batteries (30 kWh) and sodium sulphate batteries (Xiang et al., 2008).

Carbon/carbon ultracapacitors feature capacitance as high as $4000 \mathrm{~F}$ with voltage rating up to $3 \mathrm{~V}$ per cell (Gulhane et al, 2006). These very high specific-power energy-storage devices can be fully charged within a few seconds and are ideal for regenerative breaking and high acceleration of the vehicle, as they are much faster than batteries. Sadly, their low energy density does not enable them to be the principal storage devices.

Commercially available EV charging stations are spreading in countries like the U.S.A. (Fig. 18) that provide for simultaneous multiple vehicle charging per station, and authentication using RFID, IC Cards and Synchronized Cell Phone. Home charging stations are also available, as well as solar photovoltaic charging station. Perhaps the latter is a seed for the carbon-free world of the future.

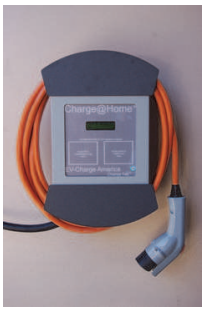

(a)

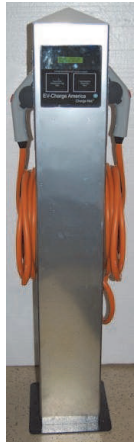

(b)

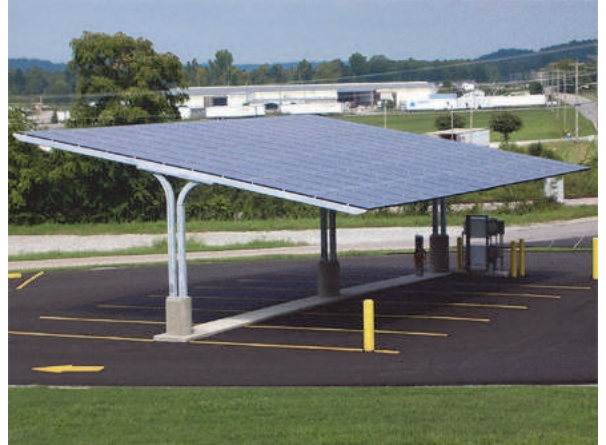

(c)

Fig. 18. Commercial charging stations for EVs: a) Home battery charging station $(240 \mathrm{~V}, 40$ A), b) commercial battery charging station ( $240 \mathrm{~V}, 40 \mathrm{~A}), \mathrm{c})$ solar powered battery charging station [EV-Charge America, 2011]

\section{Conclusion}

World concerns on climate change and the rapid vanishing of global crude-oil stock, besides air quality degradation caused by exhaust gas and car noise in megacities, guarantee a steady struggle to replace world noisy ICE-based fleet by a silent EV-based one in the 
coming decades. To that end, in spite of the enormous progress in EV technology, the following barriers are still to be overcome, before widespread use of EVs: first, the price of EVs, mainly due to battery cost, has to be lowered - which can be the result of present and future investigations on battery technology; secondly, the driving range of EVs has to be significantly extended, at reasonable battery prices; finally, huge investments in infrastructure for EVs have to be carried out. The latter is a very complex problem, which deserves cooperation of governments, carmakers, technical societies, researchers, etc, to establish standards, for instance, for battery charging infrastructure and power grid energy taxes.

\section{Acknowledgment}

The author wishes to acknowledge the financial assistance of Fundunesp (Foundation for the Development of Unesp) and the Post-Graduation Program in Mechanical Engineering of Unesp - São Paulo State University at Guaratinguetá (Brazil).

\section{References}

Ambühl, D.; Sundström, O.; Sciarretta, A. \& Guzzella, L. (2010). Explicit Optimal Control Policy and its Practical Application for Hybrid Electric Powertrains. Control Engineering Practice, Vol.18, (2010), pp. 1429-1439.

Automobile Research Bolletin 2008-8, (2008). Toyota Prius Service Precautions. March 19, 2011, Available from: <http://www.tech-cor.net/AutoResBulletin/2000-8/20008.htm>

Bakker, S. (2010). The Car Industry and the Blow-Out of the Hydrogen Hype. Energy Policy, Vol.38, (2010), pp. 6540-6544.

Bellur, D. M. \& Kazimierczuk, M. K. (2007). DC-DC Converters for Electric Vehicle Applications, Proceedings of Electrical Insulation Conference and Electrical Manufacturing Expo, pp. 286-293, 2007.

Bento, N. (2010). Dynamic Competition between Plug-in Hybrid and Hydrogen Fuel Cell Vehicles for Personal Transportation. International Journal of Hydrogen Energy, Vol.35, pp. 11271-11283.

Burke, A. F. (2007). Batteries and Ultracapacitors for Electric, Hybrid, and Fuel Cell Vehicles. Proceedings of the IEEE, Vol.95, No.4, (April 2007), pp. 806-820.

Chan, C. C. (2007). The State of the Art of Electric, Hybrid, and Fuel Cell Vehicles. Proceedings of the IEEE, Vol.95, No.4, (April 2007), pp. 704-718.

Chen, K.; Bouscayrol, A.; Berthon, A.; Delarue, P.; Hissel, D. \& Trigui, R. (2009). Global Modeling of Different Vehicles. IEEE Vehicular Technology Magazine, (June 2009), pp. 80-89.

Clement-Nyns, K.; Haesen, E. \& Driesen, J. (2011). The Impact of Vehicle-to-Grid on the Distribution Grid. Electric Power System Research, Vol.81, (2011), pp. 185-192.

EV-Charge America. March 27, 2011, Available from: <http://www.ev-chargeamerica.com> Gulhane, V.; Tarambale, M. R. \& Nerkar, Y. P. (2006). A Scope for the Research and Development Activities on Electric Vehicle Technology in Pune City, Proceedings of IEEE Conference on Electric and Hybrid Vehicles, pp. 1-8, 2006.

Kruger, P. \& Leaver, J. D. (2010). Comparative Requirements for Electric Energy for Production of Hydrogen Fuel and/or Recharging of Battery Electric Automobile 
Fleets in New Zealand and the United States. International Journal of Hydrogen Energy, Vol.35, pp. 11284-11290.

Lucena, S. E. de; Marcelino, M. A. \& Grandinetti, F. J. (2007). Low-Cost PWM Speed Controller for an Electric Mini-Baja Type Vehicle. Journal of the Brazilian Society of Mechanical Sciences and Engineering, Vol.28, No.1, 2007, pp. 21-25.

Ohn, H.; Yu, S. \& Min, K. (2010). Spark Timing and Fuel Injection Strategy for Combustion Stability on HEV Powertrain. Control Engineering Practice, Vol.18, (2010), pp. 12721284.

Maggetto, G. \& Van Mierlo, J. (2000). Electric and Electric Hybrid Vehicle Technology: a Survey, Proceedings of IEE Seminar on Electric, Hybrid and Fuel Cell Vehicles, pp. 1/11/11, 2000.

Sioshansi, R.; Fagiani, R. \& Marano, V. (2010). Cost and Emissions Impacts of Plug-in Hybrid Vehicles on the Ohio Power System, Energy Policy, Vol.38, pp. 6703-6712.

Toyota Motor Corporation. March 19, 2011, Available from: <http://www.toyota.com/prius/specs.html>

Xiang, Z.; Jia, W.; Jianzhong, Y.; Zhibiao, C.; Qinglin, H. \& Yuanzhang, H. (2008). Prospects of New Energy Vehicles for China Market, Proceedings of Hybrid and Eco-Friendly Vehicle Conference, pp. 1-8, 2008.

Wu, X.; Cao, B.; Li, X.; Xu, J. \& Ren, X. (2011). Component Sizing Optimization of Plug-in Hybrid Electric Vehicles, Applied Energy, Vol.88, pp. 799-804. 


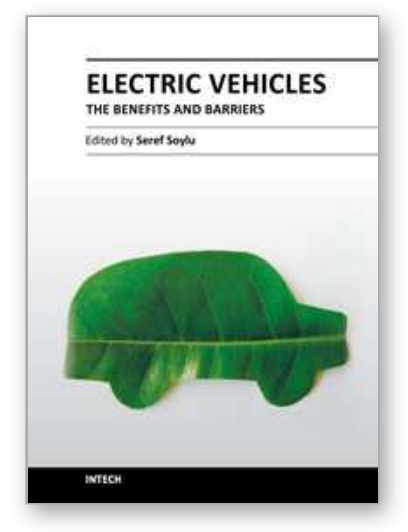

\author{
Electric Vehicles â€“" The Benefits and Barriers \\ Edited by Dr. Seref Soylu
}

ISBN 978-953-307-287-6

Hard cover, 240 pages

Publisher InTech

Published online 06, September, 2011

Published in print edition September, 2011

In this book, theoretical basis and design guidelines for electric vehicles have been emphasized chapter by chapter with valuable contribution of many researchers who work on both technical and regulatory sides of the field. Multidisciplinary research results from electrical engineering, chemical engineering and mechanical engineering were examined and merged together to make this book a guide for industry, academia and policy maker.

\title{
How to reference
}

In order to correctly reference this scholarly work, feel free to copy and paste the following:

Samuel E. de Lucena (2011). A Survey on Electric and Hybrid Electric Vehicle Technology, Electric Vehicles â€" The Benefits and Barriers, Dr. Seref Soylu (Ed.), ISBN: 978-953-307-287-6, InTech, Available from: http://www.intechopen.com/books/electric-vehicles-the-benefits-and-barriers/a-survey-on-electric-and-hybridelectric-vehicle-technology

\section{INTECH}

open science | open minds

\section{InTech Europe}

University Campus STeP Ri

Slavka Krautzeka 83/A

51000 Rijeka, Croatia

Phone: +385 (51) 770447

Fax: +385 (51) 686166

www.intechopen.com

\section{InTech China}

Unit 405, Office Block, Hotel Equatorial Shanghai

No.65, Yan An Road (West), Shanghai, 200040, China

中国上海市延安西路65号上海国际贵都大饭店办公楼 405 单元

Phone: +86-21-62489820

Fax: $+86-21-62489821$ 
(C) 2011 The Author(s). Licensee IntechOpen. This chapter is distributed under the terms of the Creative Commons Attribution-NonCommercialShareAlike-3.0 License, which permits use, distribution and reproduction for non-commercial purposes, provided the original is properly cited and derivative works building on this content are distributed under the same license. 